\title{
Organocatalysis for the Asymmetric Michael Addition of Cycloketones and $\alpha, \beta$-Unsaturated Nitroalkenes
}

\author{
Jae Ho Shim ${ }^{1, *} \mathbb{D}$, Byung Kook Ahn ${ }^{1}$, Ji Yeon Lee ${ }^{2}$, Hyeon Soo Kim ${ }^{1}$ and Deok-Chan Ha ${ }^{2, *}$ \\ 1 Department of Anatomy, Korea University College of Medicine, 46, Gaeunsa 2-gil, Seongbuk-gu, \\ Seoul 02842, Korea; abk0627@korea.ac.kr (B.K.A.); anatomykim@korea.ac.kr (H.S.K.) \\ 2 Department of Chemistry, Korea University, 145 Anam-ro Seongbuk-gu, Seoul 02841, Korea; \\ lauren3371@korea.ac.kr \\ * Correspondence: shimjh3000@korea.ac.kr (J.H.S.); dechha@korea.ac.kr (D.-C.H.); Tel.: +82-2-2286-1125 (J.H.S.)
}

Citation: Shim, J.H.; Ahn, B.K.; Lee, J.Y.; Kim, H.S.; Ha, D.-C.

Organocatalysis for the Asymmetric Michael Addition of Cycloketones and $\alpha, \beta$-Unsaturated Nitroalkenes. Catalysts 2021, 11, 1004. https:// doi.org/10.3390/catal11081004

Academic Editor:

Jean-Marc Campagne

Received: 28 July 2021

Accepted: 19 August 2021

Published: 20 August 2021

Publisher's Note: MDPI stays neutral with regard to jurisdictional claims in published maps and institutional affiliations.

Copyright: (c) 2021 by the authors. Licensee MDPI, Basel, Switzerland. This article is an open access article distributed under the terms and conditions of the Creative Commons Attribution (CC BY) license (https:// creativecommons.org/licenses/by/ $4.0 /)$.

\begin{abstract}
Michael addition is one of the most important carbon-carbon bond formation reactions. In this study, an $(R, R)$-1,2-diphenylethylenediamine (DPEN)-based thiourea organocatalyst was applied to the asymmetric Michael addition of nitroalkenes and cycloketones to produce a chiral product. The primary amine moiety in DPEN reacts with the ketone to form an enamine and is activated through the hydrogen bond formation between the nitro group in the $\alpha, \beta$-unsaturated nitroalkene and thiourea. Here, the aim was to obtain an asymmetric Michael product through the 1,4-addition of the enamine to an alkene to form a new carbon-carbon bond. As a result, the primary amine of the chiral diamine was converted into an enamine. The reaction proceeded with a relatively high level of enantioselectivity achieved using double activation through the hydrogen bonding of the nitro group and thiourea. Michael products with high levels of enantioselectivity (76-99\% syn ee) and diastereoselectivity (syn/anti $=9 / 1)$ were obtained with yields in the range of $88-99 \%$ depending on the ketone.
\end{abstract}

Keywords: organocatalyst; enantioselectivity; cycloketone; thiourea catalyst; asymmetric synthesis; Michael addition; diastereoselectivity

\section{Introduction}

In past years, reactions using metal complexes as catalysts have exhibited higher catalytic activity than that of conventional Pt complex catalysts. However, metal catalysts are expensive, and the residual metals can cause environmental problems due to disposal after use and contamination of the products [1]. Therefore, the replacement of metal catalysts with organic catalysts in some reactions may solve a significant portion of the aforementioned problems. The Michael reaction is one of the most important carboncarbon bond formation methods. Several enantioselective Michael reactions using organic catalysts are known. Among them, the proline-catalyzed reactions studied by Seebach and Blarer in 1981 have received significant attention, and many related studies have been conducted since [2-10]. Seebach and Blarer reported the Michael reaction of an $\alpha$, $\beta$-unsaturated nitroalkene using a chiral proline derivative [11,12]. In this experiment, the ketone reacts with the amino group of proline by a dehydration condensation reaction to form an enamine. Here, the enamine is the activated Michael donor, and the nitroalkene is the Michael acceptor. In 2001, when List introduced proline as an organic catalyst for the Michael reaction, the general applicability of proline and its derivatives gained increasing interest [13-15]. List assumed that acetone reacts with chiral proline to form an enamine intermediate. The reaction proceeds through a mechanism in which the nitro group is activated through the carboxylic acid and hydrogen bonding. Furthermore, the nature of the activation of the $\mathrm{NO}_{2}$ group through the hydrogen bonding was recently explained [16-19]; this result was achieved by testing various ketones and nitroalkenes. As a result, a relatively high yield was obtained in this experiment regardless of ring-forming 
and non-ring forming ketones and aromatic and aliphatic alkenes. Moreover, due to the steric effects of chiral proline, the reaction exhibited relatively high diastereoselectivity and mirror image selectivity. The advantage of this reaction is that the enamine form of the product is hydrolyzed due to $\mathrm{H}_{2} \mathrm{O}$ generated by the reaction of ketone and proline, and there is no need to add water separately. Subsequently, proline is regenerated, and the product is obtained in high yields. Moreover, this reaction can be easily carried out at room temperature. In 2006, Barbas modified the basic structure of proline and obtained a high yield and stereoselectivity using the proline-based catalyst and an acid catalyst, with brine as a solvent $[20,21]$. Recent experiments have reported high yields and selectivity by replacing the carboxylic acid group in proline with thiourea to improve hydrogen bonding [22]. Hydrogen bonding in thiourea was first reported by Jacobsen and has been applied in various reactions. Since 2006, the thiourea-based catalysts have been applied in Michael reactions as well [23,24].

Looking closely at the above-mentioned reactions using organic catalysts, the efficiency of Michael reactions using chiral amine catalysts is evident [25-38]. Although it was previously assumed that reactions using proline derivatives are limited, many previous studies have reported Michael reactions that use proline derivatives as a basic structure. Moreover, N-monoalkylated thiourea catalysts based on the basic chiral skeleton of $(\mathrm{R}, \mathrm{R})$ 1,2-diphenylethylenediamine (DPEN) can be applied to various reactions, such as the DielsAlder reaction, Aldol reaction, and Michael reaction, with relatively good yields $[9,10,39]$.

In this study, the asymmetric Michael reaction was applied to a cycloketone using ( $R, R)-1,2$-diphenylethylenediamine (DPEN) as a catalyst. This reaction was also carried out in a previous study where the primary amine group of the DPEN-based catalyst was not $N$-monoalkylated $[8,40]$. The dehydration condensation reaction of the ketone and the diamine produces an enamine. Subsequently, thiourea is introduced on the other amine group, and double hydrogen bonding occurs between the nitro group of the nitroalkene and thiourea. The regeneration of the catalyst is achieved through the hydrolysis of the activated enamine. The reaction course is determined by the attack on the electrophically activated b-position of nitroethene [16-19]. The water previously produced during the 1,4-addition hydrolyzes the enamine form of the product, thereby regenerating the catalyst. In addition, previously unreported additives were added to increase reactivity. The Michael reaction described in this study was expected to proceed with the following mechanism (Scheme 1): In particular, the presented reaction can be an attractive alternative to other known methodologies for the synthesis of 5-membered cyclic nitrones.

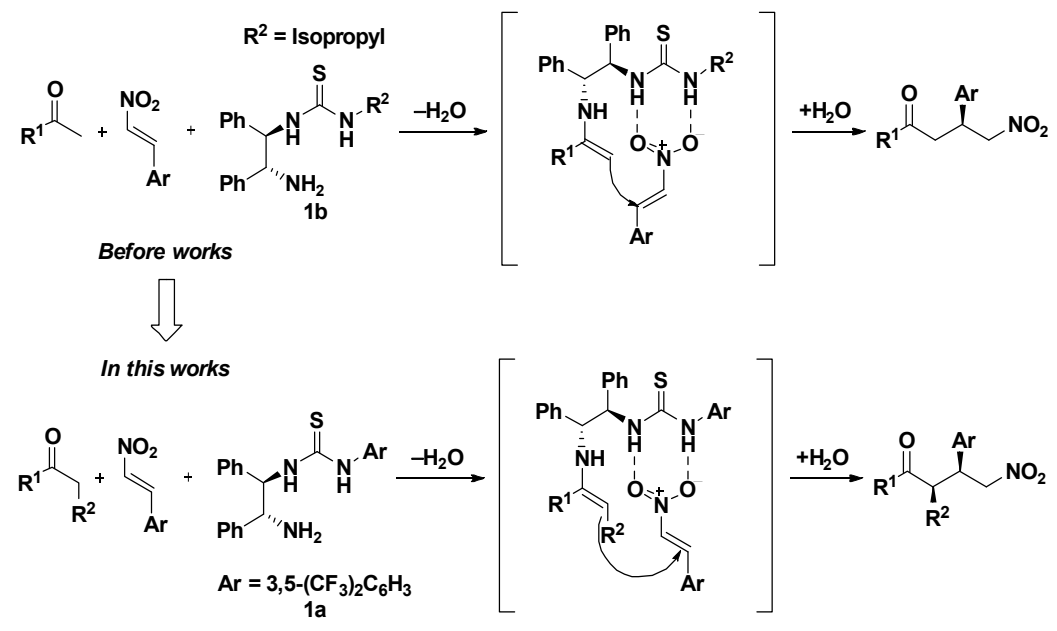

Scheme 1. Mechanism of the Michael reaction of ketones and nitroalkenes using a thiourea-based catalyst. 


\section{Results and Discussion}

2.1. Asymmetric Michael Reaction of Various Ketones and $\alpha, \beta$-Unsaturated Nitroalkenes Using a Thiourea Catalyst

In a previous study $[8,40]$, the optimized conditions for the stereoselective Michael addition reaction of acetophenone and nitrostyrene were investigated. Based on these conditions, various cycloketones, acetone and nitrostyrene derivatives were reacted in the presence of the catalyst, solvent, and a phenol group derivative (Table 1). This reaction was performed using various phenol derivatives as additives under predetermined and optimized conditions (Table 1 entry 1, 2, 3, 4, 5). Reactions with 4-nitrophenol gave relatively high yields and enantioselectivity, whereas reactions with phenol and 4-chlorophenol gave moderate yields. In addition, when catalyst $1 \mathrm{~b}$ was used under the condition of using 4-nitrophenol as an additive, lower yield and ee were confirmed compared with the case optimized in the previous literature [16-19].

Table 1. Asymmetric Michael reaction of various ketones and $\alpha, \beta$-unsaturated nitroalkenes, using a thiourea catalyst.

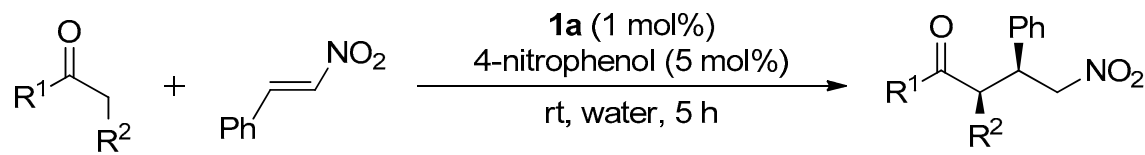

10 equiv $\quad 0.3 \mathrm{mmol} \quad$ 2a-e

\begin{tabular}{|c|c|c|c|c|c|}
\hline & \multicolumn{2}{|c|}{$0.3 \mathrm{mmol}$} & & \multicolumn{2}{|c|}{$2 a-e$} \\
\hline Entry & $\mathbf{R} 1$ & $\mathbf{R} 2$ & Yield $^{a}(\%)$ & syn/anti ${ }^{b}$ & ee (syn) ${ }^{c}(\%)$ \\
\hline $1^{d}$ & $\mathrm{CH}_{3}$ & $\mathrm{H}$ & 72 & - & 72 \\
\hline $2^{e}$ & $\mathrm{CH}_{3}$ & $\mathrm{H}$ & 81 & - & 98 \\
\hline $3^{f}$ & $\mathrm{CH}_{3}$ & $\mathrm{H}$ & 90 & - & 99 \\
\hline $4^{g}$ & $\mathrm{CH}_{3}$ & $\mathrm{H}$ & 98 & - & 99 \\
\hline 5 & $\mathrm{C}_{6} \mathrm{H}_{5}$ & $\mathrm{H}$ & 95 & - & 98 \\
\hline 6 & \multicolumn{2}{|c|}{$-\left(\mathrm{CH}_{2}\right)_{4}-$} & 99 & $90 / 10$ & 99 \\
\hline 7 & \multicolumn{2}{|c|}{$-\left(\mathrm{CH}_{2}\right)_{3}-$} & 98 & $80 / 20$ & 88 \\
\hline 8 & \multicolumn{2}{|c|}{$-\mathrm{CH}_{2} \mathrm{CH}_{2} \mathrm{OCH}_{2}-$} & 87 & $82 / 18$ & 66 \\
\hline 9 & \multicolumn{2}{|c|}{$-\mathrm{CH}_{2} \mathrm{CH}_{2} \mathrm{SCH}_{2}^{-}$} & 85 & $66 / 34$ & 94 \\
\hline
\end{tabular}

$\overline{{ }^{a}}$ isolated yields, ${ }^{b}$ diastereoselectivities were determined by ${ }^{1} \mathrm{H}$ NMR analysis, ${ }^{c}$ The ee values were determined by chiral-phase HPLC, ${ }^{d}$ used $1 \mathrm{~mol} \%$ of $1 \mathrm{~b}$ catalyst, ${ }^{e}$ used $5 \mathrm{~mol} \%$ of phenol addictive, ${ }^{f}$ used $5 \mathrm{~mol} \%$ of 4-chlorophenol, $g$ the reaction proceeded for $36 \mathrm{~h}$.

Furthermore, this reaction was performed using various ketone substrates under predetermined and optimized conditions (Table 1). Reactions involving acetones provided relatively high yields and enantioselectivity, whereas reactions involving cycloketones provided relatively low yields for sulfur and oxygen-substituted cycloketones. This result can be explained by the fact that the ketone reacts with the amino group of the catalyst to form an enamine. Due to the steric hindrance caused by the ring of the cycloketone, it is difficult for the nucleophile to approach the electrophilic nitroalkene. In addition, as the size of the ring decreases, the diastereoselectivity and enantioselectivity decrease, as described above.

\subsection{Reaction According to the Type of Acetone and $\alpha, \beta$-Unsaturated Nitroalkynes}

To verify the applicability of this reaction for aliphatic ketones under optimized conditions, acetone was reacted with various $\alpha, \beta$-unsaturated nitroalkenes. Compared to aromatic ketones, acetone exhibited poor reactivity toward this reaction. Therefore, 10 equivalents of the catalyst were used for the experiment (Table 2).

The reaction of acetone with $\alpha, \beta$-unsaturated nitroalkene proceeded for a longer duration when the nitroalkene attached to a phenyl ring with an electron-donating group was used (entry 12, Table 2). However, in the case of phenyl rings substituted with electronwithdrawing groups (entries 2,3, and 6), it was confirmed that the reaction proceeded well overall, and the duration was relatively short. This general trend can be confirmed based 
on entry 6. The reason for the increase in the reaction time is that the nucleophile is unable to approach the electrophile due to the interference caused by the 2-OMe group.

Table 2. Reaction of acetone with $\alpha, \beta$-unsaturated nitroalkenes.

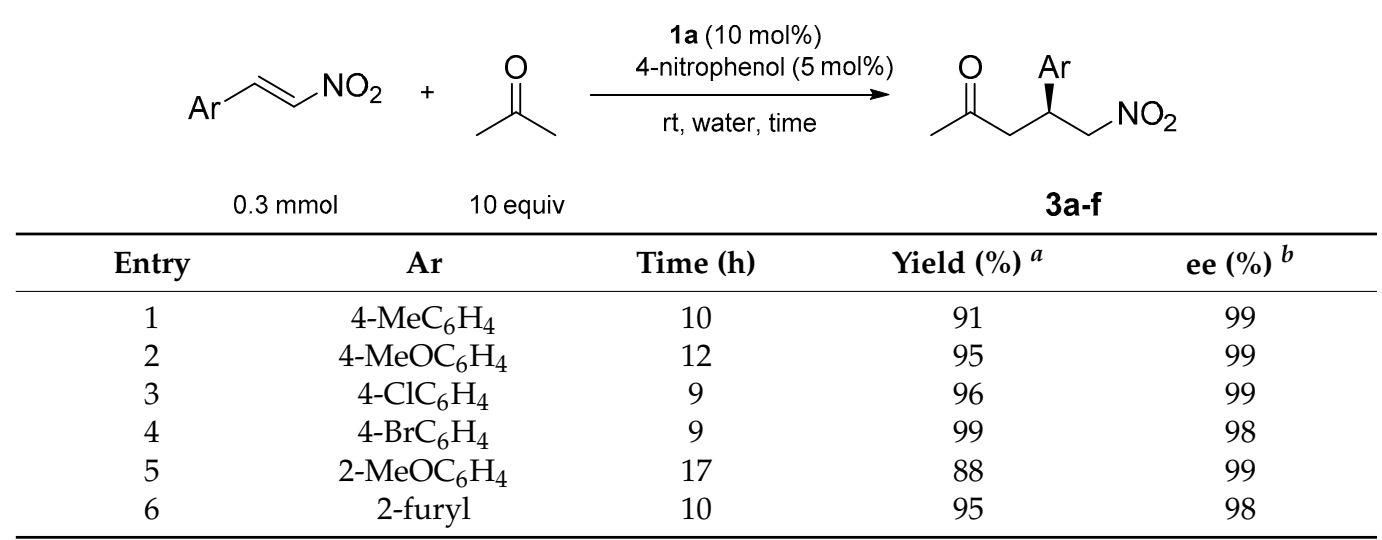

${ }^{a}$ Isolated yields, ${ }^{b}$ the ee values were determined by chiral-phase HPLC.

\subsection{Asymmetric Michael Reaction Using a Thiourea Catalyst}

These reactions were performed using various nitroalkene substrates attached to phenyl rings containing electron-withdrawing or -donating groups. When the nitroalkene bearing a phenyl ring with a halogen at the para position was used, the reaction exhibited slightly lower enantioselectivity than that using trans- $\beta$-nitrostyrene. Similarly, reactions using 2-furyl, 2-thienyl, and 2-naphthyl nitroalkenes (Table 3, entry 7, 8, and 9, respectively) exhibited relatively good enantioselectivities. In particular, the reaction with the 2-furyl derivative afforded the highest yield. Moreover, the nitroalkene attached to a phenyl ring with an electron-donating methoxy group at the fourth position showed a slightly higher yield and stereoselectivity than that with an electron-withdrawing nitro group at the fourth position. In the case of aliphatic alkenes, the reaction did not proceed. Scheme 2 shows the reaction mechanism proposed for the Michael reaction presented below.

Table 3. Asymmetric Michael reaction of the cycloketones and various $\alpha, \beta$-unsaturated nitroalkenes using the thiourea catalyst.

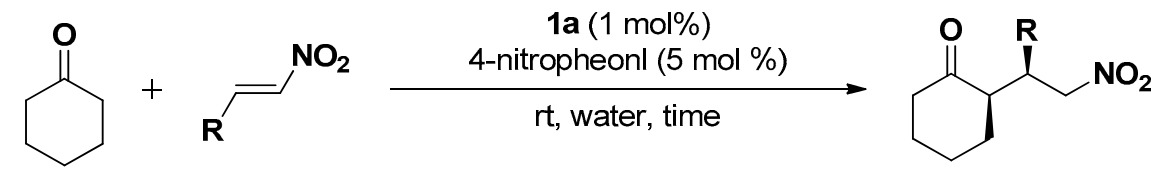

\begin{tabular}{|c|c|c|c|c|}
\hline \multirow{2}{*}{$\frac{10 \text { equiv }}{\text { Entry }}$} & \multicolumn{2}{|l|}{$0.3 \mathrm{mmol}$} & \multicolumn{2}{|c|}{$4 a-n$} \\
\hline & $\mathbf{R}$ & Yield ${ }^{a}(\%)$ & syn/anti $b$ & ee(syn) ${ }^{c}(\%)$ \\
\hline 1 & $4-\mathrm{Me}-\mathrm{C}_{6} \mathrm{H}_{4}$ & 98 & $86 / 14$ & 99 \\
\hline 2 & $4-\mathrm{i}-\mathrm{Pr}-\mathrm{C}_{6} \mathrm{H}_{4}$ & 88 & $93 / 7$ & 82 \\
\hline 3 & $4-\mathrm{F}-\mathrm{C}_{6} \mathrm{H}_{4}$ & 92 & $88 / 12$ & 99 \\
\hline 4 & $4-\mathrm{Cl}-\mathrm{C}_{6} \mathrm{H}_{4}$ & 99 & $81 / 19$ & 99 \\
\hline 5 & $4-\mathrm{Br}-\mathrm{C}_{6} \mathrm{H}_{4}$ & 97 & $85 / 15$ & 96 \\
\hline 6 & $3-\mathrm{Cl}-\mathrm{C}_{6} \mathrm{H}_{4}$ & 93 & $91 / 9$ & 96 \\
\hline 7 & 2-furyl & 92 & $92 / 8$ & 96 \\
\hline 8 & 2-thienyl & 99 & $84 / 16$ & 98 \\
\hline 9 & 2-naphthyl & 92 & $89 / 11$ & 92 \\
\hline 10 & $4-\mathrm{MeO}-\mathrm{C}_{6} \mathrm{H}_{4}$ & 99 & $91 / 9$ & 99 \\
\hline 11 & $2-\mathrm{MeO}-\mathrm{C}_{6} \mathrm{H}_{4}$ & 94 & $91 / 9$ & 99 \\
\hline 12 & $2-\mathrm{NO}_{2}-\mathrm{C}_{6} \mathrm{H}_{4}$ & 95 & $87 / 13$ & 94 \\
\hline
\end{tabular}

$\overline{{ }^{a} \text { Isolated yields, }{ }^{b} \text { diastereoselectivities were determined by }{ }^{1} \mathrm{H} \text { NMR analysis, }{ }^{c} \text { the ee values were determined }}$ by chiral-phase HPLC. 

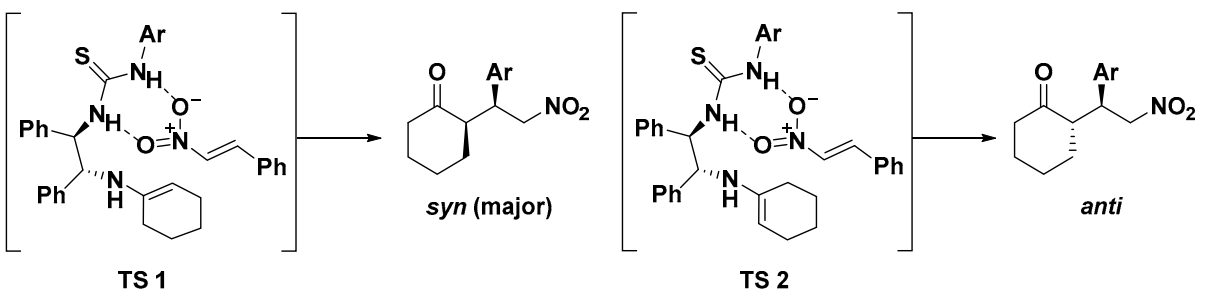

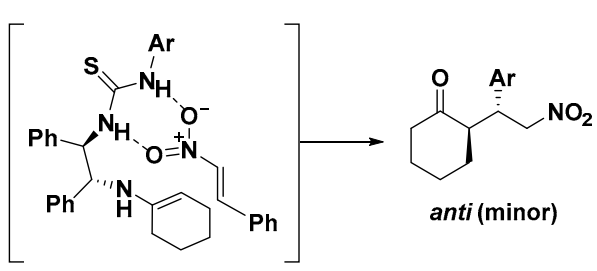

TS 3

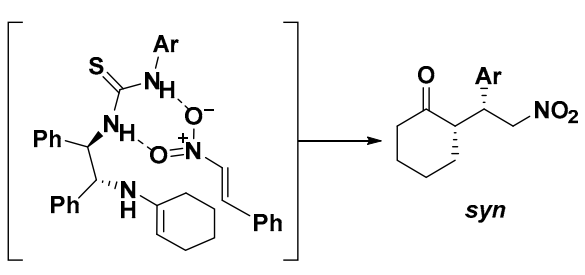

TS 4

Scheme 2. Possible stereochemical transition state models and expected syn and anti products.

As shown in Figure 1, the expected energy of transition state 1 (TS 1) was confirmed through density functional theory (DFT) calculations. The calculated results show that, compared to TS 2 (anti), TS 3 (anti), and TS 4 (syn), the syn structure of TS 1 is most stable, based on their respective Gibbs free energies. In addition, the minor TS 3 exhibited the highest free energy compared to other TS structures. Furthermore, as shown in Scheme 3, cyclohexanone reacts with the primary amine of the catalyst to form an enamine. The double bond and thiourea are located on the same side in TS 1 and TS 3, which causes less steric hindrance. Advantageously, the hydrogen bonding between the nitro group of the nitroalkene and thiourea of the catalyst causes the aromatic substituent on the alkene to be positioned in a manner similar to that of TS 1 and TS 2 with relatively lower steric hindrance; therefore, the nucleophilic enamine approaches the electrophile from the bottom. It is predicted that the $\operatorname{syn}(2 R, 1 S)$ conformation is more predominantly produced. The above reaction focuses on the double hydrogen bonds between thiourea and the nitro group. A non-polar aprotic solvent that does not interfere with hydrogen bonding is most beneficial. Furthermore, it was confirmed that the addition of an acid catalyst promotes the hydrolysis of the enamine to obtain a higher yield of the product. Based on the transition state, the ketone reacts with the amino group of proline to form the enamine, and the thiourea on the other side is hydrogen-bonded to the two oxygen atoms of the nitro group. Hence, the enamine attacks the nucleophile from below. This reaction exhibits relatively high enantioselective and diastereoselective results. When the ketone and the catalyst react to form an enamine, the double bond is formed closer to the nitroalkene. Moreover, the aromatic substituted nitroalkene is located in the direction of thiourea with relatively fewer steric hindrances.

\subsection{Application of Pancracin Intermediate Products to the Asymmetric Michael Reaction of Ketones with $\alpha, \beta$-Unsaturated Nitroalkenes}

This reaction is potentially useful in organic synthesis for carbon-carbon bond formation. For example, the nitro compound $\mathbf{4} \mathbf{k}$ was readily converted into 3-phenyloctahydroindole, $5 \mathbf{a}$. Moreover, we found that, in the presence of $\mathrm{Zn}$ powder, 41 was easily hydrogenated into the corresponding nitrone $\mathbf{5 a}$ with $95 \%$ yield. The structure of nitrone $\mathbf{5} \mathbf{a}$ was determined using ${ }^{1} \mathrm{H}$ nuclear magnetic resonance spectroscopy and mass spectrometry, which agreed well with the relative configuration described above (Scheme 3) [22,41]. 


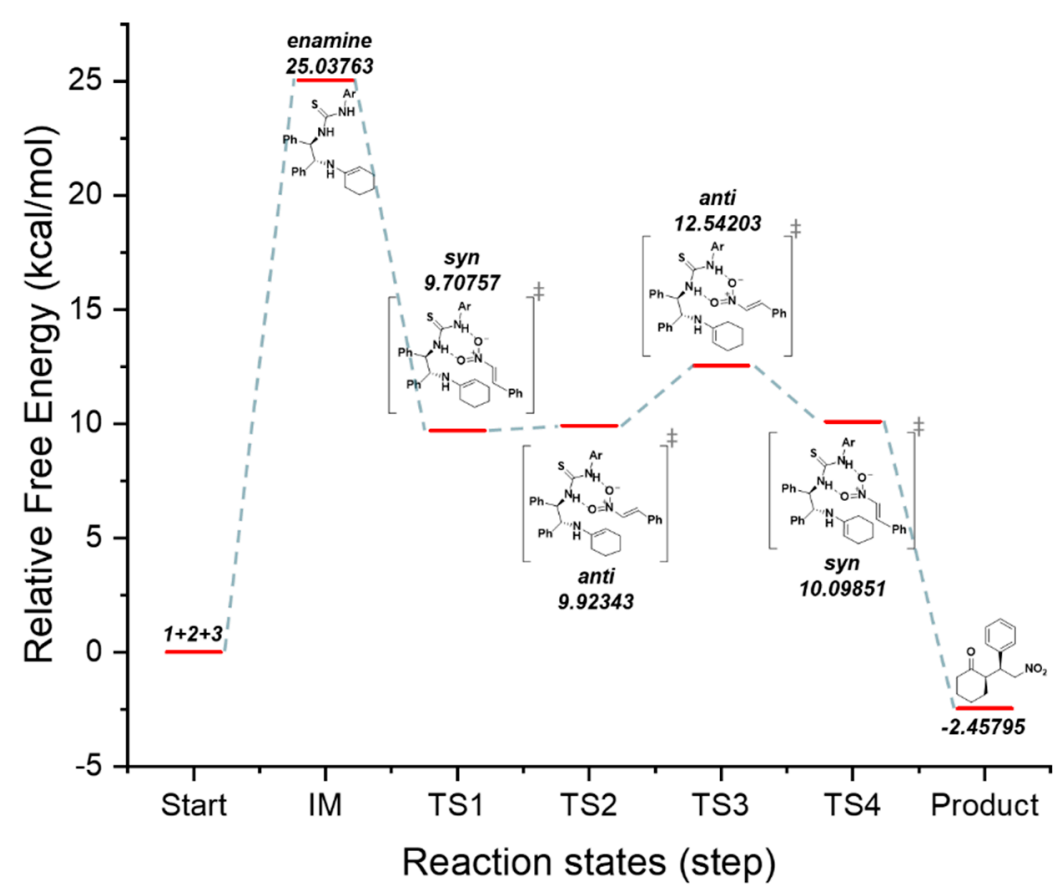

Figure 1. Proposed catalytic mechanism based on B3LYP/6-31G(d,p) calculations and the free energy diagram of the $(R, R)$-1,2-diphenylethylenediamine(DPEN)-thiourea-catalyzed enantioselective Michael reaction.

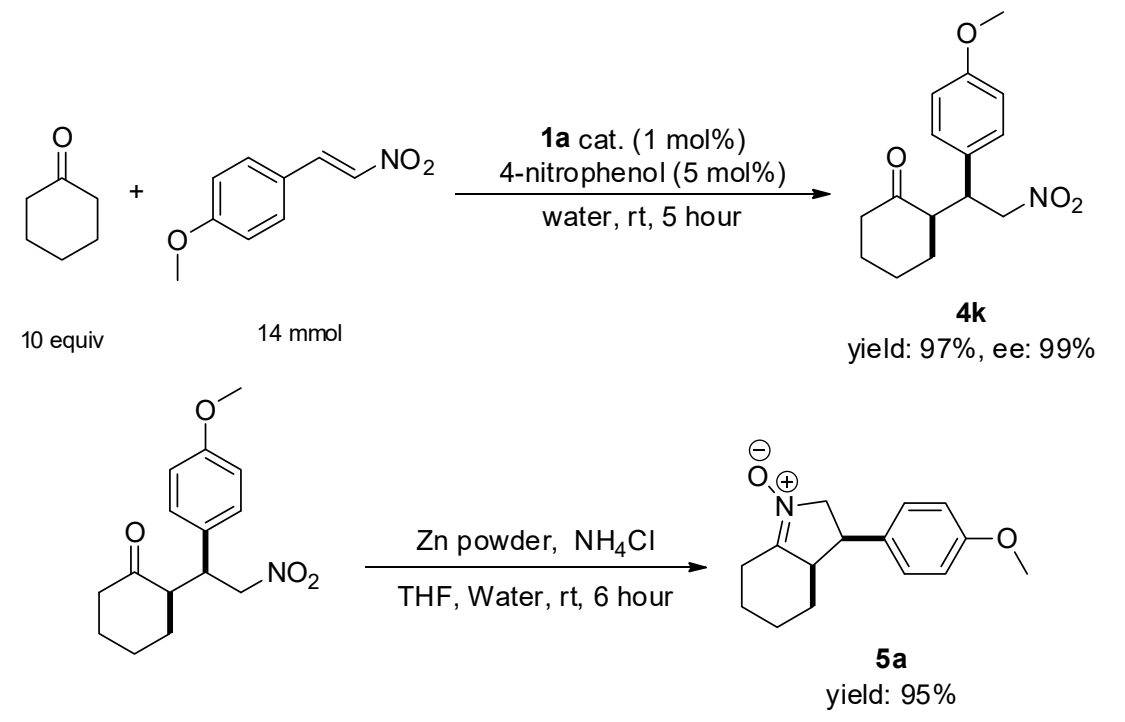

Scheme 3. Synthesis of 3-Arylhexahydroindole 1-Oxides.

\section{Materials and Methods}

\subsection{Instruments and Reagents}

IR spectrum was recorded using NICOLET 380 FT-IR spectrophotometer of Thermo electron corporation (Thermo Fisher Scientific Inc., Waltham, MA, USA), and optical rotation was measured using an auto digital polarimeter (model name: A20766 APV /6w, Rudolph Research Analytical, Hackettstown, NJ, USA). ${ }^{1} \mathrm{H}$ NMR and ${ }^{13} \mathrm{C}$ NMR spectra were obtained using Varian Gemini 300 (300, $75 \mathrm{MHz}$, Agilent, Santa Clara, CA, USA), Varian Mercury 400 (400, $100 \mathrm{MHz}$, Agilent, Santa Clara, CA, USA) and Bruker Avance 500 (500, $125 \mathrm{MHz}$, Bruker BioSpin GmbH, Silberstreifen 4, 76287 Rheinstetten, Billerica, MA, USA) using TMS as internal standards. Chiral HPLC analysis was performed using a Jasco LC-1500 Series HPLC system (JASCO, 4-21, Sennin-cho 2-chome, Hachioji, Tokyo 193-0835, Japan). All reactions were carried out under an argon environment in well-dried 
flasks in an oven. Toluene $\left(\mathrm{CaH}_{2}\right), \mathrm{THF}\left(\mathrm{Na}\right.$, benzophenone), and $\mathrm{CH}_{2} \mathrm{Cl}_{2}\left(\mathrm{CaH}_{2}\right)$ reaction solvents were purified before use. The reagents used in this study were products such as Aldrich (Louis, MO, USA), TCI (Tokyo, Japan), and if necessary, purified or dried by a known method. Merck's silica gel 60 (230-400 mech) was used as a stationary phase for column chromatography.

\subsection{Experimental Method}

\subsubsection{Synthesis of N-Mono-Thiourea Catalyst}

$(R, R)$-1.2-diphenylethylenediamine ( $200 \mathrm{mg}, 0.942 \mathrm{mmol})$ was dissolved in toluene $(1.00 \mathrm{~mL})$, followed by the addition of isothiocyanate $(0.140 \mathrm{~mL}, 0.942 \mathrm{mmol})$ at $0{ }^{\circ} \mathrm{C}$ for $1 \mathrm{~h}$ Stir. After completing the reaction with distilled water, extraction with dichloromethane ( $20 \mathrm{~mL} \times 3$ times), dehydration with $\mathrm{MgSO}_{4}$, filtration, concentration under reduced pressure, and column chromatography $\left(\mathrm{SiO}_{2}, \mathrm{EtOAc}: \mathrm{CH}_{2} \mathrm{Cl}_{2}=1: 6\right)$ to isolate the product (Scheme 4).

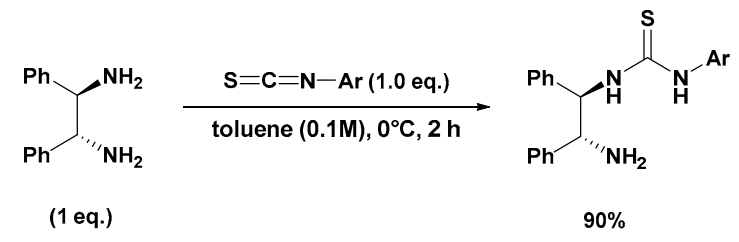

Scheme 4. Synthesis of N-mono-thiourea catalyst.

3.2.2. Asymmetric Michael Reaction of Chitons and $\alpha, \beta$-Unsaturated Nitroalkenes Using a Chiral Thiourea Catalyst

At room temperature, a thiourea catalyst $(7.3 \mathrm{mg}, 0.020 \mathrm{mmol})$, 4-nitrophenol $(5 \mathrm{~mol} \%)$ and trans- $\beta$-nitrostyrene $(30 \mathrm{mg}, 0.20 \mathrm{mmol})$ were put into a reaction vessel and then dissolved with water $(1.0 \mathrm{~mL})$ in air conditions, followed by cyclohexanone $(0.21 \mathrm{~mL}$, $2.0 \mathrm{mmol}$ ), which was added and stirred for $5 \mathrm{~h}$. After terminating the reaction with distilled water, extraction with dichloromethane $(20 \mathrm{~mL} \times 3$ times), dehydration with $\mathrm{MgSO}_{4}$, filtration, concentration under reduced pressure, and column chromatography $\left(\mathrm{SiO}_{2}\right.$, EtOAc: hexanes $\left.=5: 1\right)$ were used to isolate the product.

\subsubsection{Synthesis of 3-Arylhexahydroindole 1-Oxides}

To a solution of the $4 \mathrm{k}(300 \mathrm{mg}, 1.08 \mathrm{mmol})$ in THF $(5 \mathrm{~mL})$, zinc powder $(707 \mathrm{mg}$, $10.8 \mathrm{mmol})$ was added and a solution of $\mathrm{NH}_{4} \mathrm{Cl}(57 \mathrm{mg}, 1.08 \mathrm{mmol})$ in water $(2 \mathrm{~mL})$. The mixture was stirred vigorously at room temperature for $6 \mathrm{~h}$ and filtered. The residual solids were washed with THF, and the combined filtrates were concentrated. The residue was purified by flash column chromatography on silica gel $\left(\mathrm{CH}_{2} \mathrm{Cl}_{2} / \mathrm{MeOH}, 95 / 5\right)$ to provide $197 \mathrm{mg}(95 \%)$ of $5 \mathrm{a}$ as a white, solid foam.

\subsubsection{General Procedure of the Racemic Michael Addition}

To the trans- $\beta$-nitrostyrene ( $0.3 \mathrm{mmol})$, ketone (5 equiv.) and $20 \mathrm{~mol} \%$ of DL-Proline were added to dichloromethane $(0.1 \mathrm{M})$, and the reaction mixture was stirred at ambient temperature. The reaction conversion was monitored by TLC. After completion of about $12 \mathrm{~h}$, ethyl acetate $(0.2 \mathrm{~mL})$ was added to the reaction product. This solution was washed twice with water $(2 \times 1.0 \mathrm{~mL})$, dried over magnesium sulfate (anhydrous), and concentrated to yield the desired product. The product was purified by chromatography on a silica gel column eluted with mixed solvent (hexanes/EA, 5/1).

\subsection{Results of DFT Calculations and Discussion}

Density functional theory (DFT) calculations were performed using Gaussian 16 and Gauss-View 6.0 programs. DFT calculations were performed to show the mechanisms of substrates and catalysts. The optimized geometry was described using the B3LYP/6$31 \mathrm{G}(\mathrm{d}, \mathrm{p})$ level. After the shapes of reactants, intermediates (IM), transition states (TS), and 
products were fully optimized, zero-point energy (ZPE) was obtained through vibrational frequency calculation at the same level of theory, and the minimum or transition state of the potential energy surface (PES) was obtained. Enthalpy correction and entropy with temperature were calculated at $298 \mathrm{~K}$ and $1 \mathrm{~atm}$ pressure.

Compound Characterization Data, Copy of NMR and MASS Spectra, Copy of GC Chromatograms, DFT Calculations for all Calculated Structures of the compounds mentioned in the text (see Supplementary Materials).

\section{Conclusions}

The asymmetric 1,4-addition reaction of various ketones with nitroalkenes was catalyzed using a DPEN-based thiourea catalyst to form enamines that act as nucleophiles. Due to the double activation of the electrophilic nitro group of the alkene through hydrogen bonding with thiourea of the catalyst, this Michael 1,4-addition reaction generated products with relatively high enantioselectivity and diastereoselectivity. In addition, it is eco-friendly by using water as a solvent, and the reactivity is increased by adding 4-nitrophenol. The enamine form of the product is hydrolyzed by the $\mathrm{H}_{2} \mathrm{O}$ molecules, and the catalysts used are recovered after the reaction. In addition, to verify the general applicability of this reaction, several experiments were conducted using various ketones and nitroalkenes, which produced good results. However, a large number of catalysts and additives were used here. Therefore, the future task of optimizing these reaction conditions still remains and needs to be studied further. In addition, the drug development of chiral compounds using this synthetic approach is ongoing.

Supplementary Materials: The following are available online at https:/ / www.mdpi.com/article/10 $.3390 /$ catal11081004/s1.

Author Contributions: Conceptualization, D.-C.H. and J.H.S.; methodology, J.H.S.; software, J.H.S. and B.K.A.; validation, J.H.S., and D.-C.H.; formal analysis, J.H.S.; investigation, J.Y.L.; resources, D.-C.H.; data curation, J.H.S. and J.Y.L.; writing—original draft preparation, J.H.S.; writing—review and editing, J.H.S.; visualization, J.H.S.; supervision, D.-C.H.; project administration, J.H.S.; funding acquisition, H.S.K. All authors have read and agreed to the published version of the manuscript.

Funding: This study was supported by the Ministry of SMEs and Startups, Tech Incubator Program for startup Korea (TIPS-S2948051).

Acknowledgments: We are also grateful for the financial support provided by K.H. Kim.

Conflicts of Interest: The authors declare no conflict of interest. The funders had no role in the design of the study; in the collection, analyses, or interpretation of data; in the writing of the manuscript, or in the decision to publish the results.

\section{References}

1. Fubini, B.; Otero Arean, C. Chemical Aspects of the Toxicity of Inhaled Mineral Dusts. Chem. Soc. Rev. 1999, 28, 373-381. [CrossRef]

2. Brook, M.A.; Seebach, D. Cyclic Nitronates from the Diastereoselective Addition of 1-Trimethylsilyloxycyclohexene to Nitroolefins. Starting Materials for Stereoselective Henry Reactions and 1,3-Dipolar Cycloadditions. Can. J. Chem. 1987, 65, 836-850. [CrossRef]

3. Yamamoto, Y.; Nishii, S. The Anti-Selective Michael Addition of Allylic Organometals to Ethylidenemalonates and Related Compound. J. Org. Chem. 1988, 53, 3597-3603. [CrossRef]

4. Martens, J.; Lubben, S. Enantiomerenreine Bicyclische Pyrrolidin-Derivate:: Herstellung und Verwendung in Asymmetrischen Synthesen. Tetrahedron Lett. 1991, 47, 1205-1214. [CrossRef]

5. Saraswathy, V.G.; Sankararaman, S.J. Chemoselectivity in the Michael Addition of Silyl Enol Ethers in Lithium Perchlorate-Diethyl Ether Medium. Evidence for Facile Silyl Group Transfer to Michael Acceptors. J. Org. Chem. 1995, 60, 5024-5028. [CrossRef]

6. Alexakis, A.; Andrey, O. Diamine-Catalyzed Asymmetric Michael Additions of Aldehydes and Ketones to Nitrostyrene. Org. Lett. 2002, 4, 3611-3614. [CrossRef]

7. Dalko, P.I.; Moisan, L. In the Golden Age of Organocatalysis. Angew. Chem. Int. Ed. 2004, 43, 5138-5175. [CrossRef]

8. Shim, J.H.; Nam, S.H.; Kim, B.S.; Ha, D.C. Organocatalytic Asymmetric Michael Addition of Ketones to $\alpha$, $\beta$-Unsaturated Nitro Compounds. Catalysts 2020, 10, 618. [CrossRef]

9. Shim, J.H.; Kim, M.J.; Lee, J.Y.; Kim, K.H.; Ha, D.C. Organocatalytic Asymmetric Aldol Reaction Using Protonated Chiral 1,2-Diamines. Tetrahedron Lett. 2020, 61, 152295. [CrossRef] 
10. Shim, J.H.; Lee, M.J.; Lee, M.H.; Kim, B.S.; Ha, D.C. Enantioselective Organocatalytic Michael Reactions Using Chiral (R,R)-1,2diphenylethylenediamine-derived Thioureas. RSC Adv. 2020, 10, 31808-31814. [CrossRef]

11. Seebach, D.; Golinski, J. Synthesis of Open-Chain 2,3-Disubstituted 4-Nitroketones by Diastereoselective Michael-Addition of (E)Enamines to (E)-Nitroolefins. A Topological Rule for C, C-Bond Forming Processes Between Prochiral Centers. Helv. Chim. Acta 1981, 64, 1413-1423. [CrossRef]

12. Blarer, S.J.; Schweizer, W.B.; Seebach, D. Asymmetrische Micheal-Additionen. Praktisch Vollständigdiastereo- und Enantioselektive Alkylierungen des Enamins aus Cyclohexanon und Prolinylmethyläther. durch $\omega$-Nitrostyrole zu u-2-( $1^{\prime}$-Aryl-2' nitroäthyl)cyclohexanonen. Helv. Chim. Acta 1982, 65, 1637-1654. [CrossRef]

13. List, B.; Pojarlier, P.; Martin, H.J. Efficient Proline-Catalyzed Michael Additions of Unmodified Ketones to Nitro Olefins. Org. Lett. 2001, 3, 2423-2425. [CrossRef]

14. Seayad, J.; List, B. Asymmetric Organocatalysis. Org. Biomol. Chem. 2005, 3, 719-724. [CrossRef]

15. Mukherjee, S.; List, B.; Yang, J.W. Asymmetric Enamine Catalysis. Chem. Rev. 2007, 107, 5471-5569. [CrossRef]

16. Jasinski, R.; Dresler, E. On the Question of Zwitterionic Intermediates in the [3+2] Cycloaddition Reactions: A Critical Review. Organics 2020, 1, 49-69. [CrossRef]

17. Kącka-Zych, A.; Ríos-Gutiérrez, M.; Domingo, L.R. A molecular electron density theory study of the Lewis acid-catalyzed decomposition reaction of nitroethyl benzoate using aluminum derivatives. J. Phys. Org. Chem. 2019, 32, e3938. [CrossRef]

18. Jasinski, R. $\beta$-Trifluoromethylated nitroethenes in Diels-Alder reaction with cyclopentadiene: A DFT computational study. J. Fluor. Chem. 2018, 206, 1-7. [CrossRef]

19. Kacka, A.; Jasinski, R. A dramatic change of kinetic conditions and molecular mechanism of decomposition processes of nitroalkyl carboxylates catalyzed by ethylammonium cations. Comput. Theor. Chem. 2017, 1104, 37-42. [CrossRef]

20. Nobuyuki, M.; Watanabe, K.; Yoda, H.; Takabe, K.; Tanaka, F.; Barbas, C.F. Organocatalytic Direct Michael Reaction of Ketones and Aldehydes with $\beta$-Nitrostyrene in Brine. J. Am. Chem. Soc. 2006, 128, 4966-4967. [CrossRef]

21. Notz, W.; Tanaka, F.; Barbas, C.F. Enamine-Based Organocatalysis with Proline and Diamines: The Development of Direct Catalytic Asymmetric Aldol, Mannich, Michael, and Diels-Alder Reactions. Acc. Chem. Res. 2004, 34, 580-591. [CrossRef]

22. Cao, C.-L.; Ye, M.-C.; Sun, X.-L.; Tang, Y. Pyrrolidine-Thiourea as a Bifunctional Organocatalyst: Highly Enantioselective Michael Addition of Cyclohexanone to Nitroolefins. Org. Lett. 2006, 8, 2901-2904. [CrossRef]

23. Sigman, M.S.; Jacobsen, E.N. Schiff Base Catalysts for the Asymmetric Strecker Reaction Identified and Optimized from Parallel Synthetic Libraries. J. Am. Chem. Soc. 1998, 120, 4901-4902. [CrossRef]

24. Taylor, M.S.; Jacobsen, E.N. Asymmetric Catalysis by Chiral Hydrogen-Bond Donors. Angew. Chem. Int. Ed. 2006, 45, 1520-1543. [CrossRef]

25. Vakulya, B.; Varga, S.; Csámpai, A.; Soós, T. Highly Enantioselective Conjugate Addition of Nitromethane to Chalcones Using Bifunctional Cinchona Organocatalysts. Org. Lett. 2005, 7, 1967-1969. [CrossRef]

26. McCooey, S.H.; Connon, S.J. Urea- and Thiourea-Substituted Cinchona Alkaloid Derivatives as Highly Efficient Bifunctional Organocatalysts for the Asymmetric Addition of Malonate to Nitroalkenes: Inversion of Configuration at C9 Dramatically Improves Catalyst Performance. Angew. Chem. Int. Ed. 2005, 44, 6367-6370. [CrossRef]

27. Singh, V.; Singh, V.K. Highly Enantioselective Water-Compatible Organocatalyst for Michael Reaction of Ketones to Nitroolefins. Org. Lett. 2007, 9, 1117-1119. [CrossRef]

28. Ni, B.; Zhang, Q.; Headley, A.D. Highly Enantioselective Michael addition of Ketones to Nitroolefins Catalyzed by (S)-pyrrolidine Arenesulfonamide. Tetrahedron Asymmetry 2007, 18, 1443-1447. [CrossRef]

29. Xiong, Y.; Wen, Y.; Wang, F.; Gao, B.; Liu, X.; Huang, X.; Feng, X. A Chiral Functionalized Salt-Catalyzed Asymmetric Michael Addition of Ketones to Nitroolefins. Adv. Synth. Catal. 2007, 349, 2156-2166. [CrossRef]

30. Yacob, Z.; Shah, J.; Leistner, J.; Liebscher, J. (S)-Pyrrolidin-2-ylmethyl-1, 2, 3-triazolium Salts-Ionic Liquid Supported Organocatalysts for Enantioselective Michael Additions to $\beta$-Nitrostyrenes. Synlett 2008, 15, 2342-2344. [CrossRef]

31. Andrs, J.M.; Manzano, R.; Pedrosa, R. Novel Bifunctional Chiral Urea and Thiourea Derivatives as Organocatalysts: Enantioselective Nitro-Michael Reaction of Malonates and Diketones. Chem. Eur. J. 2008, 14, 5116-5119. [CrossRef]

32. Puleo, G.L.; Iuliano, A. Substrate Control by Means of the Chiral Cavity of Prolinamide Derivatives of Cholic Acid in the Organocatalyzed Michael Addition of Cyclohexanone to Nitroolefins. Tetrahedron Asymmetry 2008, 19, 2045-2050. [CrossRef]

33. Diez, D.; Anton, A.B.; Garcia, P.; Marcos, I.S.; Babase, P.; Urones, J.G. Synthesis of a New Organocatalyst for Michael Addition. Tetrahedron Asymmetry 2008, 19, 2088-2091. [CrossRef]

34. Mandal, T.; Zhao, C.G. Modularly Designed Organocatalyst Assemblies for Direct Nitro-Michael Addition Reactions. Angew. Chem. Int. Ed. 2008, 47, 7714-7717. [CrossRef] [PubMed]

35. Rasappan, R.; Reiser, O. Cyclohexane-1,2-diamines: Efficient Catalysts for the Enantioselective Conjugate Addition of Ketones to Nitro Olefins. Eur. J. Org. Chem. 2009, 1305-1308. [CrossRef]

36. Tan, B.; Zeng, X.; Lu, Y.; Chua, P.J.; Zhong, G. Rational Design of Organocatalyst: Highly Stereoselective Michael Addition of Cyclic Ketones to Nitroolefins. Org. Lett. 2009, 11, 1927-1930. [CrossRef]

37. Ni, B.; Zhang, Q.; Dhungana, K.; Headley, A.D. Ionic Liquid-Supported (ILS) (S)-Pyrrolidine Sulfonamide, a Recyclable Organocatalyst for the Highly Enantioselective Michael Addition to Nitroolefins. Org. Lett. 2009, 11, 1037-1040. [CrossRef] [PubMed] 
38. Freund, M.; Schenker, S.; Tsogoeva, S.B. Enantioselective nitro-Michael Reactions Catalyzed by Short Peptides on Water. Org. Biomol. Chem. 2009, 7, 4279-4284. [CrossRef] [PubMed]

39. Kim, K.H.; Lee, S.; Lee, D.W.; Ko, D.H.; Ha, D.C. Organocatalysis Using Protonated 1,2-Diamino-1,2-diphenylethane for Asymmetric Diels-Alder reaction. Tetrahedron Lett. 2005, 46, 5991-5994. [CrossRef]

40. Wang, L.; Xu, X.; Huang, J.; Peng, L.; Huang, Q.; Wang, L. Asymmetric Michael Addition of Aromatic Ketones to Nitroolefins Catalyzed by Simple Chiral Bifunctional Primary Amine-Thioureas. Lett. Org. Chem. 2010, 7, 367-372.

41. Pansare, S.V.; Ligampally, R.; Kirby, R.L. Stereoselective Synthesis of 3-Aryloctahydroindoles and Application in a Formal Synthesis of (-)-Pancracine. Org. Lett. 2010, 12, 556-559. [CrossRef] [PubMed] 